QUINTEROS, Daniel "Delitos del espacio público y el problema de la "cifra negra": una aproximación a la no-denuncia en Chile".

Polít. crim. Vol. 9, № 18 (Diciembre 2014), Art. 12, pp. 691-712.

[http://www.politicacriminal.cl/Vol_09/n_18/Vol9N18A12.pdf]

\title{
Delitos del espacio público y el problema de la "cifra negra": una aproximación a la no-denuncia en Chile
}

\author{
Daniel Quinteros R. \\ Sociólogo, Subsecretaría de Prevención del Delito \\ dquinteros@interior.gov.cl
}

\section{Resumen}

El artículo busca, en un primer nivel, conocer las características más relevantes para comprender la "cifra negra" - que alcanza al 73,1\% a nivel general- de los delitos ocurridos en el espacio público contra las personas, esto es, robo con violencia o intimidación, robo por sorpresa y hurto, los que afectan aproximadamente al $20 \%$ de la población en Chile cada año. Tras analizar la "cifra negra" con un modelo de regresión logística, según variables de i) victimización, inseguridad y reacción al delito; ii) confianza en las instituciones; y iii) otras de carácter socio-demográfico, se concluye acerca de cuáles $-y$ en qué magnitud-, son los grupos con mayores chances de no denunciar los delitos de los cuáles ha sido víctima, para finalmente relevar, en un segundo nivel, la importancia de generar iniciativas públicas que busquen potenciar la denuncia, en el entendido que permite articular mejores estrategias para la prevención, el control y la sanción de los mismos, junto con entregar una mayor y mejor atención a quienes han sufrido alguno de estos delitos.

Palabras clave: Cifra negra, denuncia, casos policiales, prevención situacional, victimización.

\begin{abstract}
The article aims, at a first level, to analyze the most important characteristics needed to understand the "dark figure" -peaking at $73,1 \%$ at a general level- for crimes of opportunity committed in public space against people, mainly thefts and robberies, which affect approximately $20 \%$ of Chilean population each year. After analyzing the "dark figure" with a logistic regression model, according to i) victimization, insecurity and reaction to crime; ii) institutional trust; and iii) and other socio-demographics variables, this work concludes about which -and what size- are the groups with higher chances of not reporting crimes in which they are victims, to finally highlight, at a second level, the importance of generating public initiatives that seek to enhance crime reporting, on the understanding that this allows the articulation of better strategies for crime prevention, control and punishment, as well as to provide more and better attention to those who have suffered any of these crimes.
\end{abstract}

Key words: Dark figure, report, crime complaints, situational prevention, victimization. 
QUINTEROS, Daniel “Delitos del espacio público y el problema de la "cifra negra": una aproximación a la no-denuncia en Chile".

\section{Introducción}

Según muestran las encuestas, en la última década la delincuencia se ha convertido en uno de los problemas más importantes para la ciudadanía y, por tanto, también para las instituciones a cargo de la prevención y el control del delito, la persecución penal, el castigo y el fortalecimiento de la seguridad pública en general. ${ }^{1}{ }^{2}$

Para hacer frente a esta realidad, el primer paso consiste en dimensionar y caracterizar este fenónemo, lo que tradicionalmente se ha realizado a través del análisis y seguimiento de las estadísticas policiales, y específicamente en nuestro país, de la información que recoge Carabineros de Chile, la Policía de Investigaciones o el Ministerio Público.

Sin embargo, las estadísticas policiales tienen una serie de sesgos ligados al interés de la autoridad por presentar cifras satisfactorias para la población, sobre todo en tiempos electorales, además de padecer limitantes relacionadas con la sobre-representación de algunos delitos -como por ejemplo el robo de vehículos y sus accesorios- y a la que se conoce como "cifra negra", es decir, delitos que no son conocidos por las autoridades y, por tanto, tampoco continúan su camino hacia el proceso penal. ${ }^{3}$

En este sentido, las encuestas de victimización, cada vez más utilizadas por diversos organismos públicos y privados, permiten reducir o mitigar el sesgo de la "cifra negra" de las estadísticas de casos policiales (denuncias y detenciones), junto con recoger otra información relevante que permita caracterizar de mejor forma la victimización, la inseguridad y otras variables de interés para el sistema, lo que se ha denominado como la "promesa fundacional" de este tipo de metodologías para medir el delito.

Quizás la gran ventaja que presenta este tipo de instrumentos para medir el delito por sobre los casos policiales u otras fuentes de información, es que precisamente permite estimar la cantidad y porporción de delitos que no son conocidos ni por las policías ni por ningún otro actor del sistema penal. En Chile, algunos estudios que han tratado de caracterizar el fenómeno de la "cifra negra", estiman que "la "cifra negra" es superior al 50\% y por tanto, el nivel de denuncia no refleja necesariamente lo que está aconteciendo efectivamente con el nivel de crimen a nivel nacional. ${ }^{4}$

En Chile, las principales encuestas relacionadas con temáticas de delincuencia son la Encuesta Nacional Urbana de Seguridad Ciudadana (en adelante, ENUSC) y el Índice Paz Ciudadana-Adimark, de carácter anual y semestral, respectivamente. A partir de la primera encuesta antes mencionada, la ENUSC -en su versión 2009-, lo que se busca es realizar un

\footnotetext{
${ }^{1}$ MINISTERIO DEL INTERIOR, Encuesta Nacional Urbana de Seguridad Ciudadana, Santiago: Gobierno de Chile, 2009.

${ }^{2}$ UNIVERSIDAD DIEGO PORTALES, Séptima Encuesta Nacional UDP, Santiago: Instituto de Ciencias Sociales, UDP, 2011.

${ }^{3}$ SOZZO, Máximo, ¿Contando el Delito? Análisis Crítico y Comparativo de las Encuestas de Victimización en Argentina, Buenos Aires: Universidad Nacional del Centro de la Provincia de Buenos Aires, 2003.

4 BENAVENTE, José Miguel y CORTÉS, Enrique, Delitos y sus denuncias: La cifra negra de la criminalidad en Chile y sus determinantes, Santiago: Departamento de Economía, Universidad de Chile, 2006, p. 3.
} 
Polít. crim. Vol. 9, № 18 (Diciembre 2014), Art. 12, pp. 691-712.

[http://www.politicacriminal.cl/Vol_09/n_18/Vol9N18A12.pdf]

análisis que permita conocer con mayor profundidad la no-denuncia, a partir de la influencia de diversos factores relacionados con victimización, inseguridad, exposición al delito y otras variables de interés.

Es necesario señalar que la decisión de utilizar la mencionada encuesta del año 2009 y no la de los años siguientes, que podrían mostrar resultados más actualizados, responde a que, no obstante la metodología del levantamiento de información así como el tamaño muestral se han mantenido constantes, el cuestionario sufrió grandes modificaciones por considerarse que habían preguntas que no tenían variación en el tiempo y engrosaban la encuesta, ${ }^{5}$ siendo eliminadas justamente muchas de las preguntas que interesan incluir en el presente análisis.

\section{Victimización y no-denuncia: una encrucijada para la prevención.}

Como se puede observar en el Gráfico 1.1, la proporción de hogares víctima de al menos un delito durante el año 2009, a nivel nacional, fue del 33,6\%, siendo sólo superado por las cifras reportadas en las versiones $2010(28,2 \%), 2011(31,1 \%)$ y $2012(26,3 \%){ }^{6}$

\section{Gráfico 1.1 Victimización General y Denuncia por Región}

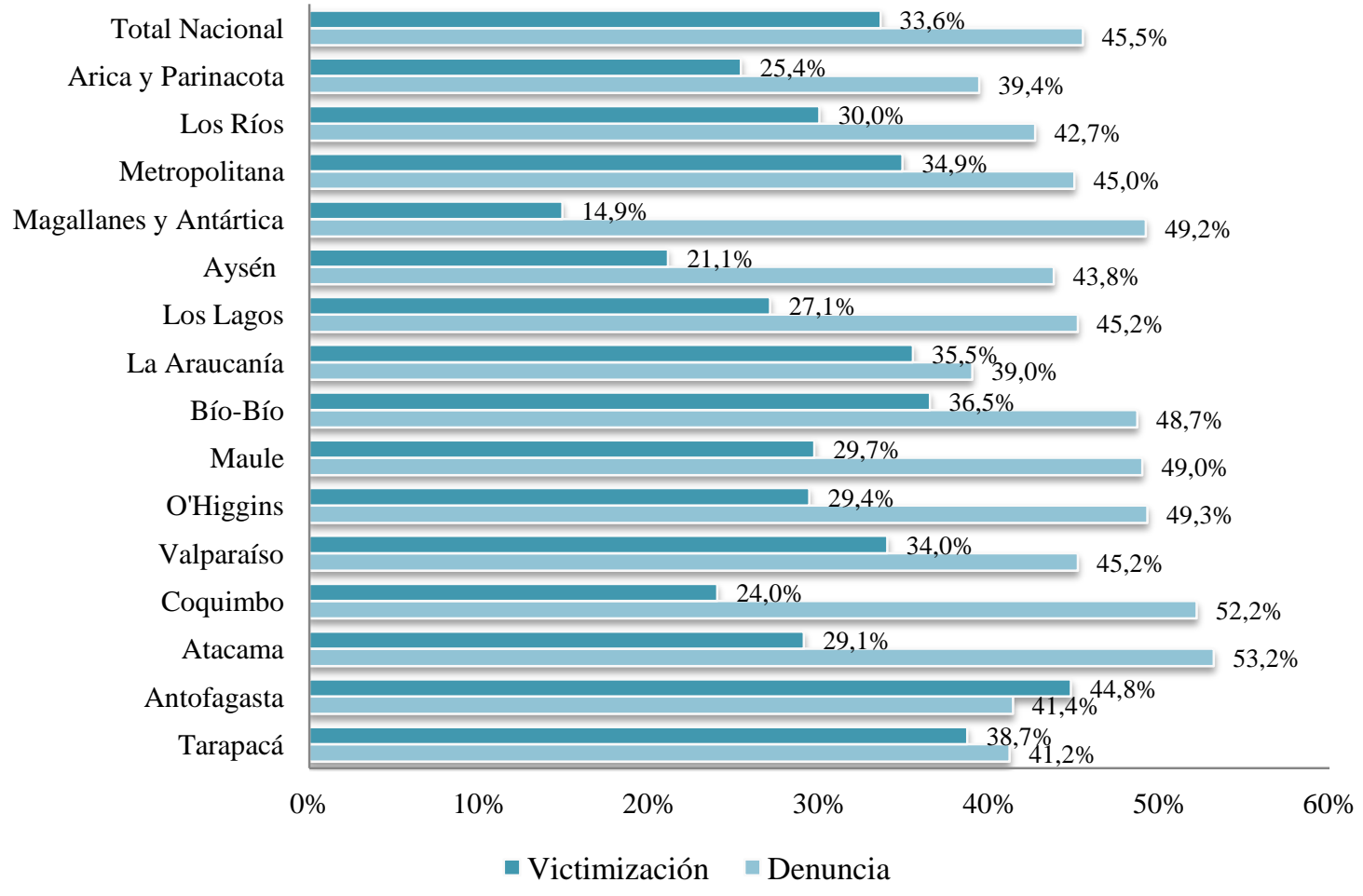

Fuente: Elaboración propia a partir de la ENUSC 2009.

\footnotetext{
${ }^{5}$ SUBSECRETARÍA DE PREVENCIÓN DEL DELITO, Los perfeccionamientos de la ENUSC en el tiempo. Minuta explicativa. Santiago: Ministerio del Interior y Seguridad Pública, Gobierno de Chile, 2012.

${ }^{6}$ La encuesta se aplicó por primera vez el año 2003 y, luego, anualmente a partir del año 2005.
} 
QUINTEROS, Daniel “Delitos del espacio público y el problema de la "cifra negra": una aproximación a la no-denuncia en Chile".

Esta cifra muestra un patrón de comportamiento altamente diverso entre las diferentes regiones del país, el que varía entre un 14,9\% de la Región de Magallanes y Antártica, hasta un 44,8\% en la región de Antofagasta. Cabe destacar que las regiones más pobladas del país, Metropolitana, Valparaíso y Bío Bío, marcan significativamente sobre el promedio nacional, registrando niveles de victimización de 34,9\%, 34,0\% y 36,5\% respectivamente.

Ahora bien, como se ha mencionado anteriormente, no todos los delitos ocurridos son denunciados o conocidos por las autoridades, por lo que resulta interesante explorar los niveles autoreportados de denuncia de los delitos sufridos por el encuestado o algún otro miembro de su hogar. En este sentido, a nivel nacional, la proporción del total de los delitos ocurridos que se denuncian llega a un $45,5 \%$, manteniéndose relativamente constante a lo largo de todo el país, entre un 39,0\% en la Región de la Araucanía y un 52,2\% y 53,2\% en las regiones de Coquimbo y Atacama, respectivamente.

Estas cifras resultan altamente preocupantes desde el punto de vista de la política pública en materia de seguridad ciudadana, toda vez que los esfuerzos públicos de la última década sobre todo después de la entrada en vigencia de la Reforma Procesal Penal- han estado enfocados de manera importante en la atención de las víctimas. "La ley $\mathrm{N}^{\circ} 19.640$ del año 1999 asigna al Ministerio Público o Fiscalía la tarea de proteger a las víctimas y testigos de los hechos delictuales durante las diligencias propias del proceso penal"?

Asimismo, existen otras instituciones del Estado que también prestan servicios de atención a víctimas. El Ministerio del Interior y Seguridad Pública cuenta actualmente con 47 Centros de Apoyo a Víctimas (CAVD), además de liderar y coordinar la Red de Asistencia a Víctimas (RAV) que integra a todas las instancias que toman contacto con las víctimas, luego de ocurrido el delito. Esta red incluye, además del Ministerio del Interior y Seguridad Pública, al Servicio Nacional de Menores (SENAME), las Corporaciones de Asistencia Judicial -ambas dependientes del Ministerio de Justicia-, el Ministerio de Salud, el Servicio Nacional de la Mujer (SERNAM), el Ministerio Público, Carabineros de Chile y la Policía de Investigaciones.

Es importante tener en cuenta que lo anterior se enmarca en el giro dado por la criminología durante la segunda mitad del siglo XX, desde la criminología crítica hacia el nuevo paradigma de la victimología, el cual busca darle un papel más importante a la víctima no sólo en el proceso penal -que tradicionalmente le entrega un papel secundario a ésta, toda vez que vela por los intereses del Estado en la persecución penal y no necesariamente (o en absoluto) por los de las víctimas y sus derechos-, sino también en el estudio y análisis del delito, en tanto el delito es entendido como una interacción social y por tanto, con inherentes relaciones de poder cuya falta podría ser un importante elemento victimizador. ${ }^{8}$ "La víctima comienza a ser considerada en el estudio, con el objetivo de conocer el impacto sufrido por la acción delictiva, y no tan sólo de forma bidireccional -víctima/delincuente-,

\footnotetext{
${ }^{7}$ VARELA J., Fernanda, "Desafíos de la política de atención a víctimas". Conceptos, №27 (2012), pp. 1-18, p. 1.

${ }^{8}$ LARRAURI, Elena, La Herencia de la Criminología Crítica. Madrid: Siglo Veintiuno, 2000.
} 
sino que también multidimensional, obligando este enfoque al estudio de otras personas que intervienen en el proceso victimal".?

Sin embargo, según las cifras antes presentadas, más de la mitad de las víctimas nunca llegan a entrar en contacto con el sistema penal, ni mucho menos con la atención de víctimas, lo que se vuelve aún más problemático si se considera que las policías están hoy dirigiendo sus estrategias para combatir el delito y distribuir los recursos policiales a través de sistemas de información georreferenciados, los que se construyen a partir de los casos policiales conocidos por las autoridades, esto es, denuncias y detenciones.

Por tanto, considerando lo expuesto hasta este punto, es posible plantearse la idea de que el sistema social del control formal del delito se encuentra hoy ante una encrucijada nada fácil de resolver: no conociendo prácticamente nada sobre los delitos que no se denuncian y sus víctimas, que representan más de la mitad de la actividad delictual del país, elabora estrategias para la prevención y el control de éstos en función de las denuncias, a la vez que promueve programas de asistencia y atención a víctimas cuya cobertura está estructuralmente condicionada a un universo potencial muy inferior al total real de víctimas de la delincuencia en el país.

Lo anterior no significaría un problema mayor si es que la pérdida de información se comportara de manera uniforme a través de las diferentes variables que son hoy posibles de conocer. Sin embargo, como pretende demostrar el presente estudio, la no-denuncia está fuertemente condicionada según el tipo de delito del que se haya sido víctima, la posibilidad de haber sido víctima en más de una ocasión, la confianza que éstas tengan sobre las instituciones del sistema, la sensación de inseguridad y exposición al delito de las mismas y ciertas otras características propias de las víctimas, como su edad, nivel socioeconómico y nivel educacional, entre otras.

Por otra parte, es necesario delimitar la diversidad del problema delictual a considerar en el presente análisis. Tal como lo señala el segundo objetivo estratégico del Plan de Seguridad Pública 2010-2014, "Plan Chile Seguro", los delitos en el espacio público representan la mitad de los delitos que ocurren en Chile anualmente: "Durante este período, se pondrá especial foco en los delitos que ocurren en el espacio público, que corresponden a robos por sorpresa, robos con violencia o intimidación y robos de vehículo y accesorios de vehículos, los que en su conjunto representan la mitad de los delitos que afectan a los chilenos". ${ }^{10}$

Lo anterior muestra la importancia de focalizar los esfuerzos públicos en materia de seguridad ciudadana no sólo de acuerdo a variables geográficas o sociodemográficas, sino también en cuanto a la tipología de delitos que se busca atacar con mayor fuerza, sobre todo si se considera que solamente los cuatro delitos antes mencionados, explican cerca del $50 \%$ de toda la incidencia delictual en el país, a la que es posible integrar el hurto, bajo el entendido de que -tal como muestra el Gráfico 1.2- del total que declara haber sido o no

\footnotetext{
9 CIFUENTES C., María Fernanda, Experiencia Internacional en Sistemas de Tratamiento y Apoyo a Víctimas de Delitos, BLANCO, Javiera (Ed.), UCINF - Paz Ciudadana, 2006, p. 10.

${ }^{10}$ MINISTERIO DEL INTERIOR Y SEGURIDAD PÚBLICA, Chile Seguro: Plan de Seguridad Pública 2010-2014. Santiago: Gobierno de Chile, 2010.
} 
QUINTEROS, Daniel "Delitos del espacio público y el problema de la "cifra negra": una aproximación a la no-denuncia en Chile".

víctima de algún delito en el espacio público, éste afecta a un 9,1\% de los hogares en el país.

\section{Gráfico 1.2 Victimización de Hogares por Delitos en el Espacio Público según Delito}

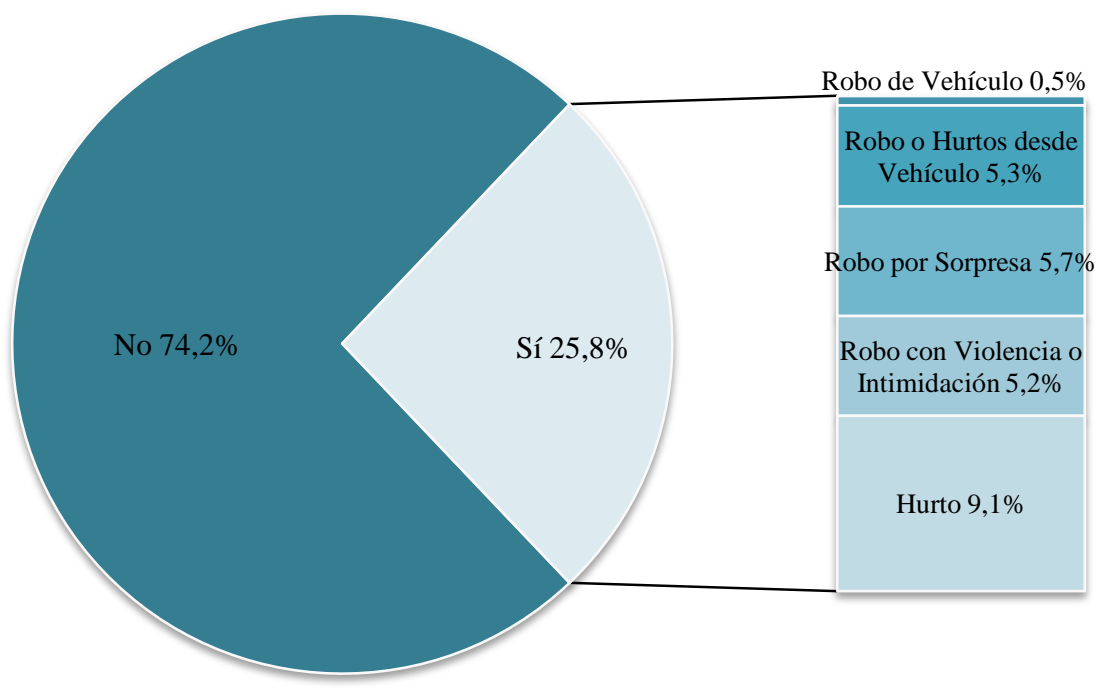

Fuente: Elaboración propia a partir de la ENUSC 2009.

Es así que el presente trabajo busca, en un primer nivel, conocer las características más relevantes que permiten comprender la no-denuncia de los delitos ocurridos en el espacio público que afectaron a las personas que declaran haber sido víctima de al menos uno de ellos durante el año 2009; todo con la intención de relevar, en un segundo nivel, la importancia de generar iniciativas públicas que busquen potenciar la denuncia, en el entendido que permite articular mejores estrategias para la prevención, el control y la sanción de los mismos, junto con entregar una mayor y mejor atención a quienes han sufrido alguno de estos delitos.

Para esto, se observarán ciertas características de las víctimas en función de si denunció o no los delitos que declara, para luego, a través de la creación de un modelo de regresión logística, determinar la probabilidad de que una persona que ha sido víctima de uno de estos delitos, lo denuncie o no, en función de las variables que se incluirán, de las cuales ya se han dado ciertas luces en los párrafos precedentes.

Considerando lo anterior, es necesario relizar una precisión adicional sobre el universo del cuál se pueden hacer inferencias a partir de los casos disponibles, puesto que la unidad de análisis para las variables relativas a victimización y denuncia son los hogares urbanos; mientras que, por otra parte, para las variables sociodemográficas y las relativas a inseguridad, exposición al delito y evaluación de servicios, entre otras, la unidad de análisis son las personas mayores de 15 años, que viven en hogares urbanos de las 101 comunas desde donde se levantó la información. 
Polít. crim. Vol. 9, № 18 (Diciembre 2014), Art. 12, pp. 691-712.

[http://www.politicacriminal.cl/Vol_09/n_18/Vol9N18A12.pdf]

Por tanto, para eliminar este sesgo, sólo se considerarán para el análisis que sigue: (a) los tres delitos del espacio público contra las personas -a saber, robo por sorpresa, robo con violencia o intimidación y hurto-, que (b) le hayan ocurrido directamente al entrevistado/a, pudiendo de esta forma contrastar la información relativa a la victimización y la denuncia, junto a todas las demás variables disponibles, entendiendo que todas se refieren a la misma unidad de análisis, una vez seleccionados sólo los casos que satisfagan ambas condiciones.

\section{Características de la no-denuncia.}

Como se muestra en el Gráfico 2.1, la cifra negra para delitos en el espacio público alcanza un $69,6 \%$ a nivel general, mostrando amplias disparidades según el tipo de delito del que se haya sido víctima. A modo de contexto general, mientras para el robo de vehículo la cifra negra alcanza un bajo 8,6\% -situación que puede estar principalmente motivada por los seguros asociados a la pérdida del bien-, para el resto de los delitos las cifras se disparan a un 55,0\% para el robo con violencia o intimidación en las personas, seguido de un 69,5\% para el robo o hurto desde vehículo, $70,5 \%$ para el robo por sorpresa y 75,2\% en el caso del hurto.

Gráfico 2.1 Distribución de las Denuncias según Tipo de Delito

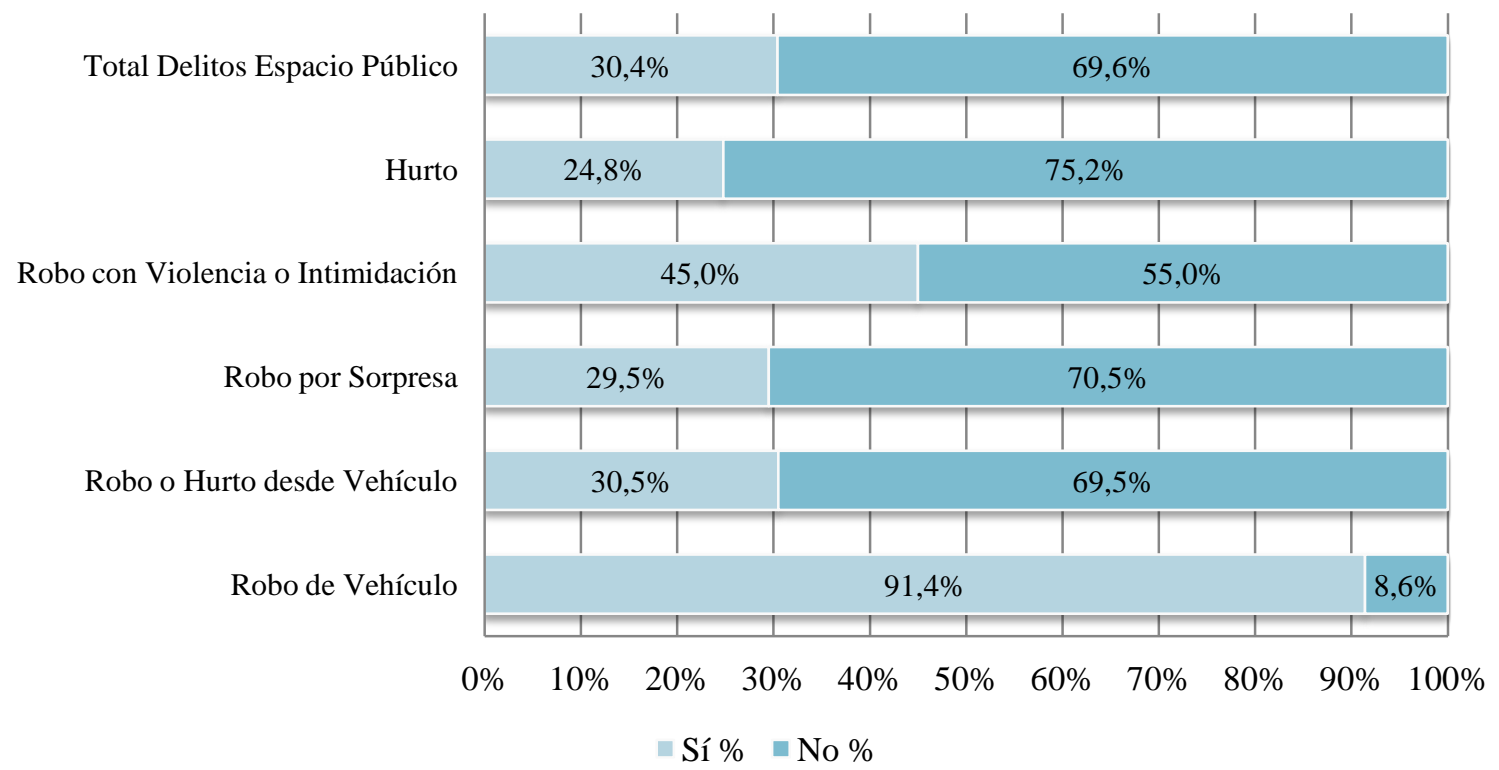

Fuente: Elaboración propia a partir de la ENUSC 2009.

Es decir, a la luz de los datos presentados en el Gráfico 1.2 y 2.1, el delito con el nivel más bajo de cifra negra -el robo de vehículo- es justamente el que menos incidencia tiene en el global de delitos cometidos, ya que sólo un $0,5 \%$ de los hogares del país fue víctima de este delito durante el 2009. A la inversa, el hurto, que afecta al 9,1\% de los hogares, presenta el nivel más alto de no-denuncia con un 75,2\%. Resulta llamativo observar que el robo por sorpresa y el robo con violencia o intimidación, ambos con una relativa alta incidencia en el total de delitos que se cometen en el espacio público -afectando al 5,7\% y 5,2\% de los 
QUINTEROS, Daniel “Delitos del espacio público y el problema de la "cifra negra": una aproximación a la no-denuncia en Chile".

hogares respectivamente-, presentan niveles de no-denuncia bastante altos: 7 de cada 10 "lanzazos"11 y entre 5 y 6 de cada 10 "asaltos", ${ }^{12}$ no se denuncian.

Ahora bien, del total de delitos en el espacio público que afectan a las personas, el 46,8\% afectó directamente al entrevistado/a, lo que equivale a 1.195.119 personas, siendo éste el universo a partir del cual se extrae toda la información que sigue. ${ }^{13}$

Si se observan los niveles de denuncia y no-denuncia en función del tipo de delito del que se haya sido víctima y la cantidad de veces que se ha visto afectado por al menos uno de ellos - tal como se muestra en el Gráfico 2.2-, es posible observar que la probabilidad de no denunciar el delito sufrido, cuando se ha sido víctima de sólo uno de los tres delitos aquí considerados, es mayor para el caso del hurto con un 79,0\%, seguido del robo por sorpresa con un $72,3 \%$ y el robo con violencia o intimidación con un $60,2 \%$.

Gráfico 2.2 Denuncia de los Delitos en el Espacio Público contra las Personas según Tipo de Delito y Cantidad de Veces que ha sido Víctima

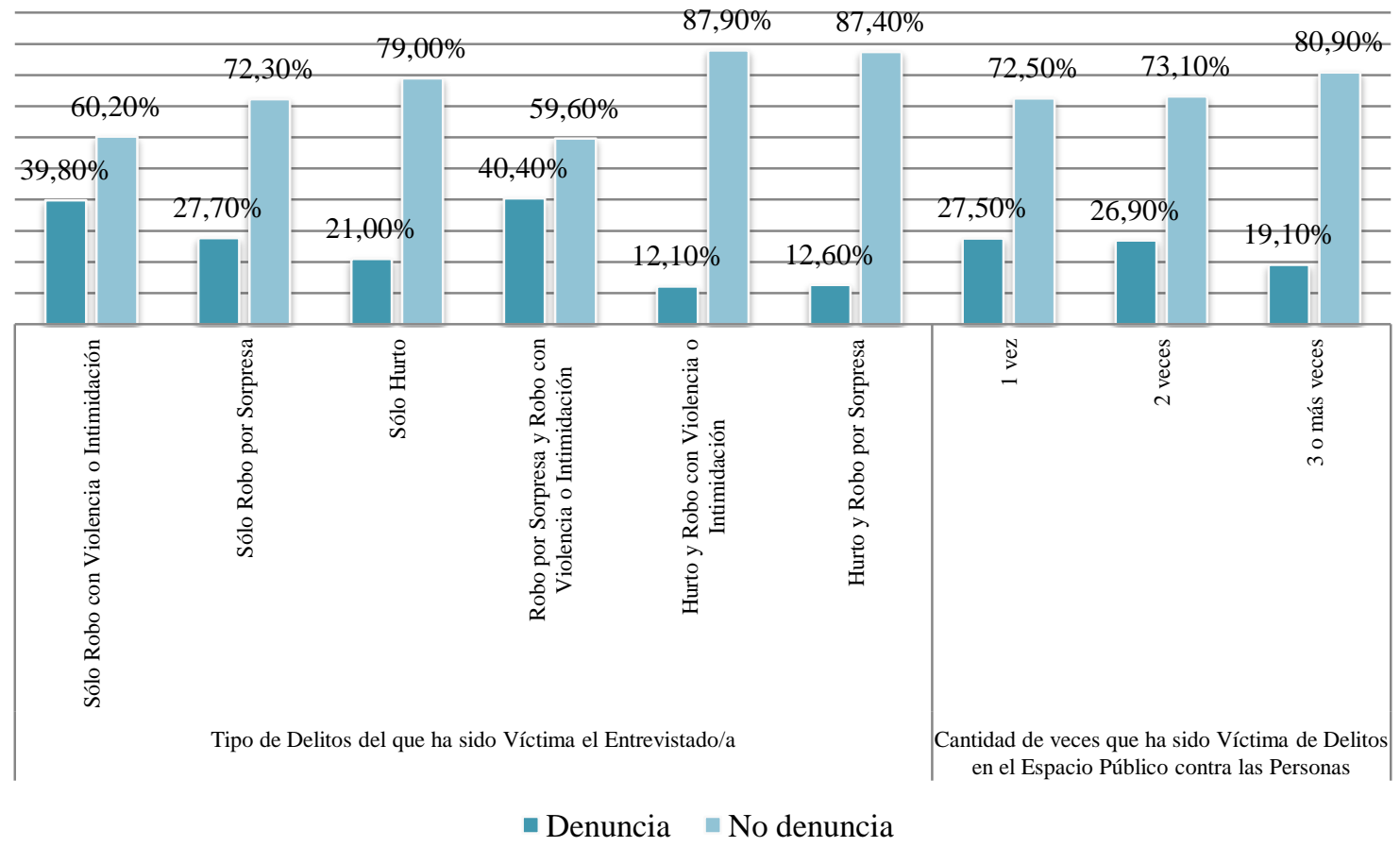

Fuente: Elaboración propia a partir de la ENUSC 2009.

No obstante lo anterior, cuando se ha sido víctima de más de un tipo de delito, resulta llamativo observar que la probabilidad de no denunciar el hecho delictual acontecido crece

\footnotetext{
${ }^{11}$ Denominación para el delito de robo por sorpresa.

${ }^{12}$ Denominación para el delito de robo con violencia o intimidación.

${ }^{13}$ Es necesario mencionar que para llegar a esta cifra, se aplicó el factor de expansión correspondiente a personas para las 15 regiones del país, cosa que se explica con mayor detalle en: Instituto Nacional de Estadísticas. Encuesta Nacional Urbana de Seguridad Ciudadana ENUSC 2009. Informe: Diseño de la Metodología Muestral. Santiago: INE, 2010.
} 
enormemente si dentro de las categorías posibles, se encuentra el hurto. Cuando se ha sido víctima de robo con violencia o intimidación y, además, robo por sorpresa, la probabilidad de no denunciar al menos uno de los delitos sufridos es de 59,6\%, mientras que cuando se ha sido víctima de hurto y robo con violencia o intimidación, la misma probabilidad alcanza un $87,9 \%$ y un $87,4 \%$ si además del hurto se fue víctima de robo por sorpresa.

Otro aspecto muy importante en torno a la victimización, es la cantidad de veces que se ha sido víctima de un delito, lo que se conoce como "re-victimización". A modo de referencia, durante el año 2011, a nivel nacional, "el porcentaje de hogares que declara haber sido victimizado sólo una vez es de $20,2 \%$, dos a tres veces $8,8 \%$ y cuatro o más veces $2,2 \%$ ". 14 Así, se observa una tendencia de que a mayor nivel de revictimización, mayor el nivel de la no denuncia, dado que quienes sólo han sido víctima una sóla vez, no denuncian en el $72,5 \%$ de los casos, mientras que quienes han sido víctimas dos veces no denuncian en el $73,1 \%$ de los casos; lo que aumenta drásticamente a un $80,9 \%$, si se ha sido víctima en tres o más ocasiones.

Por otra parte, si se observan las diferencias según el perfil sociodemográfico de las víctimas expuesto en el Gráfico 2.3, es posible observar que los jóvenes entre 15 y 29 años, seguidos por los mayores de 60 años, son quienes menos denuncian este tipo de delitos, con un $77,7 \%$ y $73,5 \%$ de no denuncia respectivamente, versus un $64,8 \%$ de las personas entre 45 y 59 años. Al contrario, no es posible detectar grandes diferencias por género, con niveles de no denuncia de un $73,1 \%$ para mujeres y un $73,2 \%$ para hombres.

El nivel educacional alcanzado por las víctimas también pareciera ser un factor que discrimina entre la denuncia y la no denuncia, dado que aquellos que sólo alcanzaron educación media o básica e inferior, tienen niveles de no denuncia de 76,5\% y 72,2\%, a la vez que aquellos que alcanzaron la educación superior o post unversitaria, presentan niveles de cifra negra inferiores al 69\%. Esto sin duda tiene un correlato con el nivel socioeconómico de las víctimas, ya que todos los grupos muestran cifras superiores al $70 \%$ -con el peak de 75,6\% en el grupo E-, a excepción del grupo $\mathrm{ABC} 1$, donde prácticamente la situación se invierte. Son más los delitos que se denuncian $(60,7 \%)$ que los que nunca llegan a ser conocidos por las autoridades $(39,3 \%)$.

14 SUBSECRETARÍA DE PREVENCIÓN DEL DELITO. ENUSC 2011 Resultados País, Santiago: Ministerio del Interior y Seguridad Pública, Gobierno de Chile, 2011, p. 15. 
QUINTEROS, Daniel "Delitos del espacio público y el problema de la "cifra negra": una aproximación a la no-denuncia en Chile".

\section{Gráfico 2.3 Denuncia de los Delitos en el Espacio Público contra las} Personas según Perfil Sociodemográfico

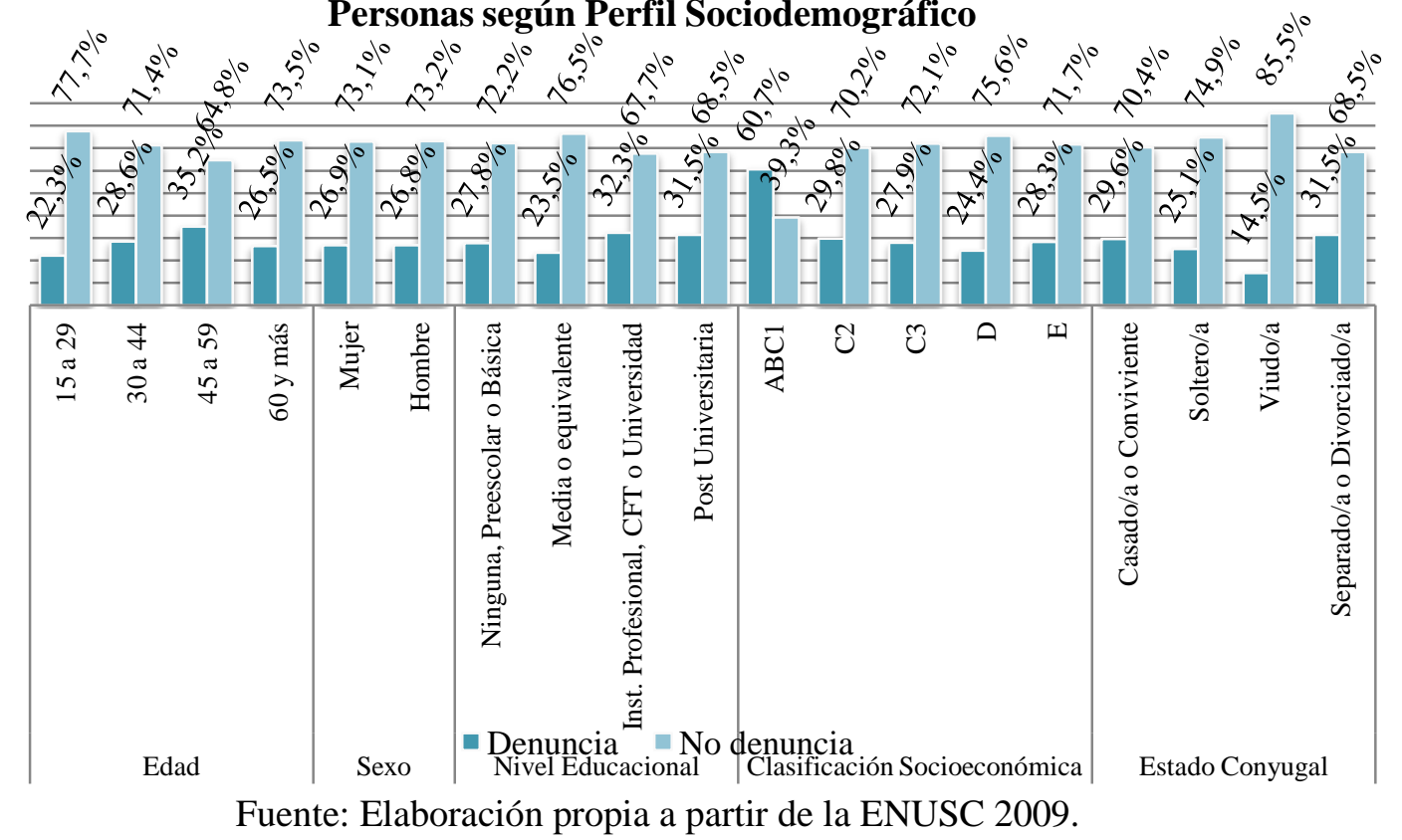

Fuente: Elaboración propia a partir de la ENUSC 2009.

Pareciera que el estado conyugal también puede ser un factor determinante a la hora de establecer diferencias por grupos en cuanto a la denuncia de los delitos sufridos: quienes se encuentran casados o conviviendo, no denuncian el 70,4\% de los delitos, mientras que los solteros/as no lo hacen en un 74,9\% y los separados/as, anulados/as o divorciados/as en un $68,5 \%$. Llama la atención que los viudos/as no denuncian el 85,5\% de los delitos que sufren, cifra bastante más alta que cualquier otra categoría aquí mencionada.

En tercer lugar, si se analizan las diferencias en función de ciertas variables ligadas a la inseguridad y la reacción frente al delito, es posible afirmar que quienes piensan que la delincuencia disminuyó en el último año, tienden a denunciar más (62,2\% de no denuncia) que aquellos que piensan que la delincuencia se mantuvo o aumentó. De manera similar, en relación a cuánto le afecta la delincuencia en su calidad de vida, también es posible observar una tendencia de que mientras menos se sienta afectado por ésta, mayor nivel de cifra negra: quienes señalan que no le afecta en nada, no denuncian en un $80 \%$, mientras que en aquellos que declaran sentirse muy afectados, la no denuncia cae a un 71,5\%. 
Polít. crim. Vol. 9, № 18 (Diciembre 2014), Art. 12, pp. 691-712.

[http://www.politicacriminal.cl/Vol_09/n_18/Vol9N18A12.pdf]

\section{Gráfico 2.4 Denuncia de los Delitos en el Espacio Público contra las Personas según Inseguridad y Reacción frente al Delito}

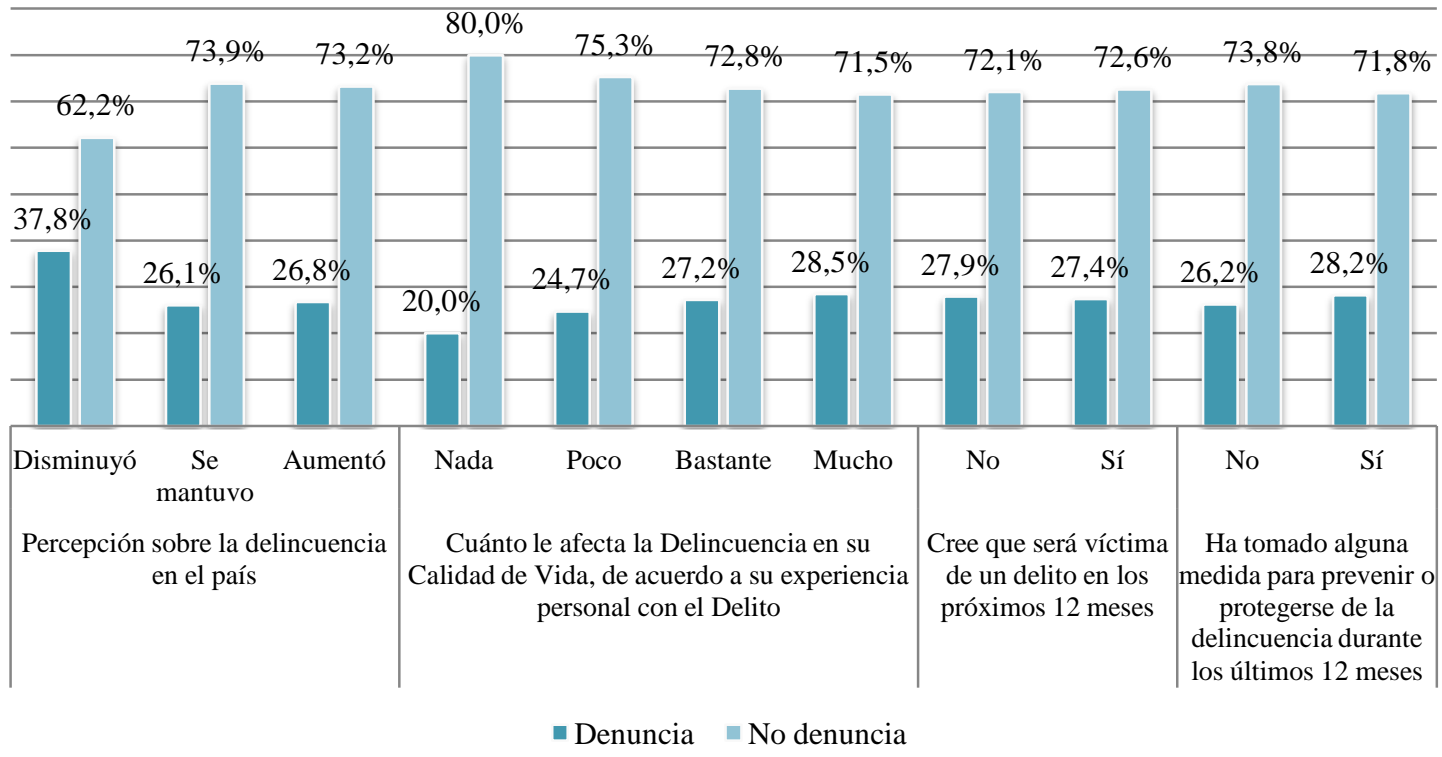

Fuente: Elaboración propia a partir de la ENUSC 2009.

Finalmente, era interesante observar las diferencias en los niveles de denuncia según la confianza que tiene la víctima sobre las instituciones que intervienen en el control social del delito y su persecución. Se eligieron las cinco que se describen a continuación, puesto que son las que mayor importancia tienen para la seguridad ciudadana, según los/as mismos/as entrevistados/as: quienes tienen mucha confianza en el gobierno, no denuncian el 78,3\%, versus el $70,5 \%$ de quienes tienen poca confianza en éste; sorprendentemente, quienes tienen ninguna confianza en los Tribunales de Justicia o el Ministerio Público, tienen el menor nivel de no denuncia $(71,7 \%$ y $71,0 \%)$; por último, quienes no tienen ninguna confianza en las policías, son quienes, en mayor proporción, no denuncian $-76,8 \%$ en el caso de Carabineros y 75,4\% en el caso de la Policía de Investigaciones-. 
QUINTEROS, Daniel "Delitos del espacio público y el problema de la "cifra negra": una aproximación a la no-denuncia en Chile".

\section{Gráfico 2.5 Denuncia de los Delitos en el Espacio Público contra las Personas según Confianza en las Instituciones}

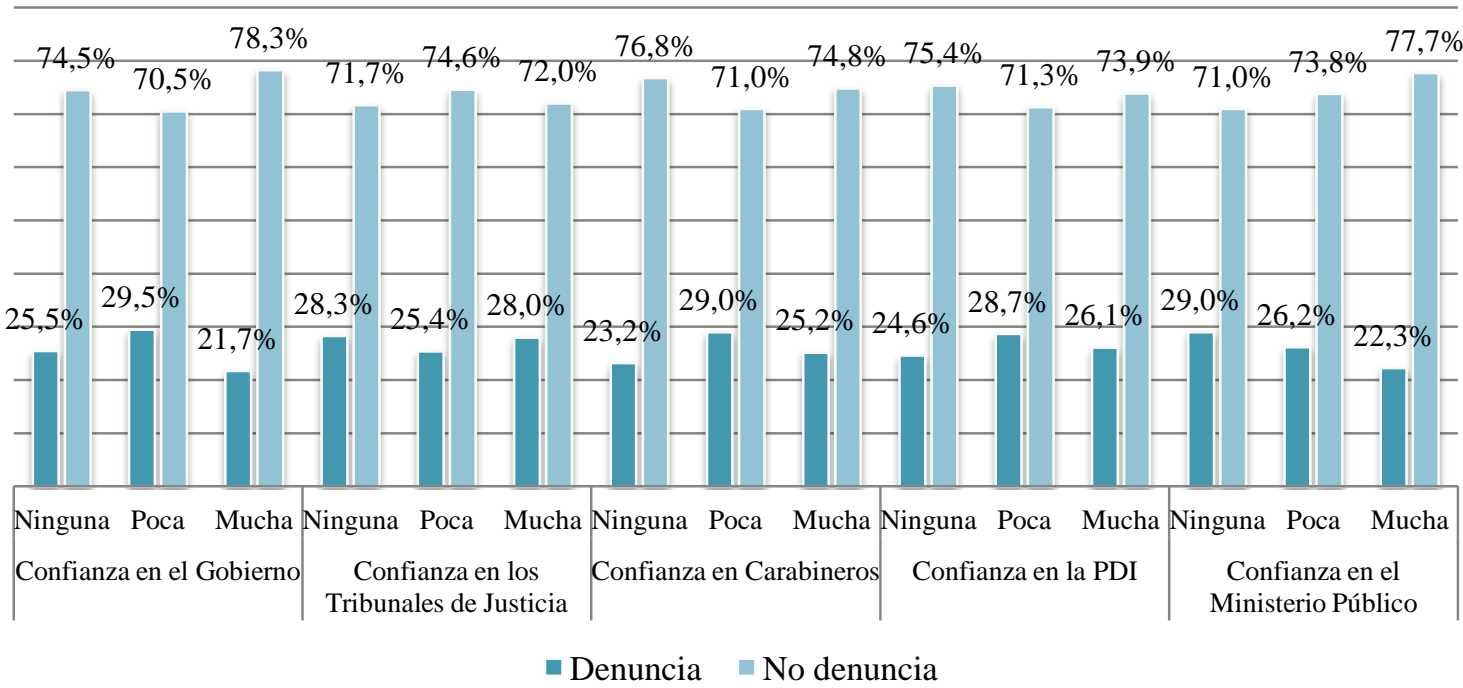

Fuente: Elaboración propia a partir de la ENUSC 2009.

\section{Resultados y conclusiones.}

A continuación se exponen los principales hallazgos de la presente investigación, tras la construcción de un modelo de regresión logística binaria utilizando como variable dependiente la no-denuncia de los delitos en el espacio público contra las personas, que describe las relaciones de chances u odds ratio entre diversas categorías o grupos de personas, de acuerdo a cuatro grandes dimensiones, las que refieren a: i) la cantidad y categoría de la victimización declarada; ii) la edad, nivel socioeconómico y nivel educacional, entre otras variables sociodemográficas; iii) la percepción sobre delincuencia, inseguridad y reacción frente al delito y; iv) la confianza que tiene la víctima sobre los actores que, entiende, son más relevantes en materia de seguridad ciudadana.

La Tabla $1.1^{15}$ resume los coeficientes logísticos para cuatro modelos que se exponen como referencia, siendo el último de ellos el más relevante, estadísticamente más robusto e interesante de analizar. Asimismo, la Tabla 1.2 muestra los coeficientes de chances a partir de los cuáles se desarrolla la lectura que sigue, los que pueden ser entendidos como factores de riesgo o de protección, según sea el caso, para que la persona no denuncie los delitos que ha sufrido.

En este sentido, resulta interesante observar que, por ejemplo, quienes han sido víctima sólo de robo por sorpresa, tienen 2,5 chances más de no denunciar estos delitos que quienes han sido víctima sólo de robo con violencia o intimidación, lo que aumenta a 3,31 si se ha sido víctima de hurto con respecto al mismo grupo de referencia. Esta relación aumenta significativamente si se ha sido víctima de más de uno de estos delitos, pero siempre

\footnotetext{
${ }^{15}$ Ver Anexo 1.
} 
incluyendo el hurto, ya que, como se desprende de la Tabla 1.2, cundo el hurto va acompañado de robo por sorpresa, hay 8,053 chances más de no denunciar el ilícito que cuando se ha sido víctima sólo de robo con violencia o intimidación, cifra que aumenta a 8,684 chances si se ha sido víctima de hurto y robo con violencia o intimidación, sobre quienes sólo han sido víctimas de este último.

Además, cuando se ha sido víctima en dos ocasiones, se tiene un 29,9\% menos de chanches de denunciar el delito, mientras que cuando se ha sido víctima en tres ocasiones o más, hay un $8,2 \%$ más de chances de no hacerlo; con respecto a quienes han sido víctima sólo una vez. Lo anterior indica dos cosas importantes: por un lado muestra que más que la cantidad de veces, lo que influye con mayor fuerza es si se ha sido víctima de más de uno de estos delitos y, en segundo lugar, que el hurto afecta notoriamente las chanches de llegar a denunciar un delito del cuál se ha sido víctima, probablemente por su difícil detección y, por tanto, sus limitadas probabilidades de enfrentar un proceso penal.

Por otra parte, la evidencia aquí encontrada sugiere que a menor edad, mayor la tendencia a no denunciar los delitos, ya que mientras el grupo entre 45 a 59 años tiene sólo un 8,2\% y los que se encuentran entre los 30 y 44 tienen un 66,1\% más de chances de no denunciar que los mayores de 60 años, esta cifra se eleva para el caso de los jóvenes entre 15 a 29 años, con un 310,5\% más de chances o, lo que es igual, 3,105 chances más.

Donde las diferencias en las relaciones de chances se vuelven más dramáticas, es cuando se compara por grupo socioeconómico. Los grupos tienen entre casi 6 y poco más de 8 chanches más de no denunciar un delito que el grupo $\mathrm{ABC} 1$, siendo el grupo $\mathrm{D}$ el que muestra mayores diferencias, con 8,355 veces más de chances de no denunciar que el grupo ABC1. A su vez, si se observa el nivel educacional, quienes sólo alcanzaron nivel "media o equivalente" tienen $26,1 \%$ más de chances de no denunciar que aquellos con educación de postgrado, magíster o doctorado.

En cuanto a la situación o estado conyugal de la personas, los casados/as o convivientes tienen $21,8 \%$ más de chances de no denunciar que aquellos que están separados/as o divorciados/as y los solteros/as tienen 16,6\% más de chances que el mismo grupo de referencia. Llama la atención que sean los viudos/as quienes mayor riesgo tienen a no denunciar, con casi 4 veces más de chances que los que están separados/as o divorciados/as. En este sentido, cuando se observan diferencias por género y aporte al ingreso del hogar, se observa que mientras los hombres tienen $31,7 \%$ más de chances que las mujeres para no denunciar, quienes aportan al ingreso del hogar tienen 5,4\% menos de chances de no denunciar que quienes no aportan al ingreso del hogar, es decir, quien aporta al ingreso del hogar tiene una tendencia leve pero mayor a denunciar.

Ahora bien, con respecto a las variables sobre percepción, hay que comenzar advirtiendo que quienes consideran que la delincuencia aumentó durante el último año tienen 2,155 chances más de no denunciar los delitos que aquellos que consideran que la delincuencia disminuyó en el mismo período, lo que disminuye a 1,99 chances más para quienes consideran que el nivel de delincuencia se mantuvo sin alteraciones. 
QUINTEROS, Daniel "Delitos del espacio público y el problema de la "cifra negra": una aproximación a la no-denuncia en Chile".

En esta línea, cuando se consulta sobre cuánto afecta la delincuencia la calidad de vida del entrevistado, no se observan grandes diferencias, excepto con respecto a quienes señalan que no le afecta en nada con un 13,9\% menos de chances que quienes declaran que les afecta mucho. Esto contrasta con la información sobre quienes creen que serán víctimas de un delito en los próximos doce meses, quienes tienen un 7,6\% menos de chances que aquellos que no creen que serán víctimas; a la vez que no se observan grandes diferencias, aunque estadísticamente significativas, entre quienes han tomado alguna medida para protegerse o prevenir la delincuencia, con un 1,4\% más de chances que quienes no lo han hecho.

Finalmente, la confianza en las instituciones muestra resultados bastante dispares. A excepción de la confianza en los Tribunales de Justicia, donde quienes dicen tener poca o ninguna confianza tienen entre 1,7 y 19 chances más de no denunciar que quienes tienen mucha confianza en éstos, para las demás instituciones analizadas, el tener poca o ninguna confianza sobre las mismas reduce las chances de no denunciar los delitos entre un $2 \%$ y un $31 \%$, dependiendo del grado de confianza y la institución en cuestión.

La evidencia hasta aquí mostrada sugiere que los grupos de mayor riesgo para no denunciar los delitos, tienen relación con el nivel socioeconómico, la edad y el/los tipo/s de delito/s del/los que se haya sido víctima. Así, los jóvenes de grupo socioeconómico D que ha sido afectado por un hurto, entre otros, es claramente, a la luz de los datos, un grupo que tiene un riesgo muchísimo mayor de no denunciar en comparación con, por ejemplo, adultos mayores de 60, del grupo ABC1 y con educación superior.

Lo anterior muestra la importancia de generar estrategias de fomento a la denuncia de manera focalizada en los grupos más vulnerables a no denunciar estos hechos delictuales, toda vez que, como ya se ha mencionado, no sólo quedan sin entrar nunca en contacto con alguna parte del sistema de atención a víctimas, sino que, lo que es peor, el sub-reporte de los mismos conlleva a generar estrategias de prevención y control del delito que contienen un sesgo importante, toda vez que la no-denuncia de los mismos, como se ha mostrado acá, no se distribuye de forma uniforme a través de todos quienes han sido víctimas, sino que responde a marcados patrones y características propias de cada individuo.

Por último, es necesario recalcar que lo expuesto aquí tan sólo busca levantar y describir una problemática que, a grandes rasgos, tiene dos dimensiones: una relativa a la política pública, tanto de prevención del delito como de atención a víctimas, y otra de carácter más metodológico, que busca poner el acento en la poca fiabilidad que tiene un instrumento que pierde casi un $70 \%$ de información de los delitos con mayor ocurrencia en el país y de forma marcadamente desigual según el perfil de la víctima.

En este sentido, la investigación acá presentada más que buscar una profundidad mayor en la discusión y definición de aspectos de gran importancia sobre la cifra negra, buscó aportar información empírica que presentara el problema y permitiera abrir futuras pistas de investigación en un tema muy poco explorado en Chile, contribuyendo así al debate criminológico relativo a la no denuncia de una parte importante de los delitos que ocurren en el país. 
QUINTEROS, Daniel "Delitos del espacio público y el problema de la "cifra negra": una aproximación a la no-denuncia en Chile".

Polít. crim. Vol. 9, № 18 (Diciembre 2014), Art. 12, pp. 691-712.

[http://www.politicacriminal.cl/Vol_09/n_18/Vol9N18A12.pdf]

\section{BIBLIOGRAFÍA}

BENAVENTE, José Miguel y CORTÉS, Enrique, Delitos y sus denuncias: La cifra negra de la criminalidad en Chile y sus determinantes. Santiago: Departamento de Economía, Universidad de Chile, 2006.

CENTRO ESTRATÉGICO DE ANÁLISIS DEL DELITO, Los perfeccionamientos de la ENUSC en el tiempo. Minuta explicativa. Subsecretaría de Prevención del Delito. Santiago: Ministerio del Interior y Seguridad Pública, 2012.

CIFUENTES C., María Fernanda, Experiencia Internacional en Sistemas de Tratamiento y Apoyo a Víctimas de Delitos. BLANCO, Javiera (ed.), Santiago: UCINF - Paz Ciudadana, 2006.

INSTITUTO NACIONAL DE ESTADÍSTICAS, Encuesta Nacional Urbana de Seguridad Ciudadana ENUSC 2009. Informe: Diseño de la Metodología Muestral. Santiago: INE, 2010.

LARRAURI, Elena, La Herencia de la Criminología Crítica. Madrid: Siglo Veintiuno, 2000.

MINISTERIO DEL INTERIOR Y SEGURIDAD PÚBLICA, Gobierno de Chile, Encuesta Nacional Urbana de Seguridad Ciudadana. Santiago : Gobierno de Chile, 2009. , Chile Seguro: Plan de Seguridad Pública 2010-2014. Santiago: s.n., 2010.

SOZZO, Máximo, ¿Contando el Delito? Análisis Crítico y Comparativo de las Encuestas de Victimización en Argentina. Buenos Aires: Universidad Nacional del Centro de la Provincia de Buenos Aires, 2003.

SUBSECRETARÍA DE PREVENCIÓN DEL DELITO, ENUSC 2011 Resultados País. Ministerio del Interior y Seguridad Pública. Santiago: Gobierno de Chile, 2011.

UNIVERSIDAD DIEGO PORTALES, Séptima Encuesta Nacional UDP. Instituto de Ciencias Sociales. Santiago: UDP, 2011.

VARELA J., Fernanda, Desafíos de la política de atención a víctimas. Santiago: Paz Ciudadana, Marzo de 2012, Conceptos, pp. 1-18.

\section{ANEXO 1}

\section{A. Características Metodológicas de la Base de Datos}

- Nombre: Encuesta Nacional Urbana de Seguridad Ciudadana (ENUSC), 2009.

- Diseño Muestral: "Muestra probabilística, estratificada geográficamente y por tamaño poblacional en el área Urbana, trietápica, con probabilidad de selección de 
QUINTEROS, Daniel "Delitos del espacio público y el problema de la "cifra negra": una aproximación a la no-denuncia en Chile".

la Unidad de Primera Etapa (manzanas) proporcional al tamaño en relación al número de viviendas y al número de manzanas, en cada subgrupo". ${ }^{16}{ }^{17}$

○ Unidad de Primera Etapa: Manzanas

- Unidad de Segunda Etapa: Viviendas particulares ocupadas

- Unidad de Tercera Etapa: Personas de 15 o más años

- Marco Muestral: Marco Muestral Maestro (MMM) basado en Censo 2002 y actualizado el año 2007.

- Población Objetivo: Hogares que habitan las viviendas particulares ocupadas y los mayores de 15 años que la componen.

- Ámbito Geográfico: Nacional-Urbano.

- Nivel de Estimación: Nacional urbano, regional urbano y comunal urbano para 101 comunas del país.

- Tamaño Muestral: 25.933 viviendas.

- Error Muestral: 0,2\% a nivel Nacional, igual o inferior a 3\% a nivel regional e inferior al $5 \%$ a nivel comunal.

\footnotetext{
${ }^{16}$ Para conocer los tamaños de los subgrupos, ver "Anexo 1" en Instituto Nacional de Estadísticas, 2010

17 Instituto Nacional de Estadísticas. Encuesta Nacional Urbana de Seguridad Ciudadana ENUSC 2009. Informe: Diseño de la Metodología Muestral. Santiago: INE, 2010.
} 
QUINTEROS, Daniel "Delitos del espacio público y el problema de la "cifra negra": una aproximación a la no-denuncia en Chile".

Polít. crim. Vol. 9, № 18 (Diciembre 2014), Art. 12, pp. 691-712.

[http://www.politicacriminal.cl/Vol_09/n_18/Vol9N18A12.pdf]

\section{B. Tablas}

Tabla 1.1 Resumen de los coeficientes logísticos para modelos sobre la No-Denuncia de Delitos en el Espacio Público Contra las Personas

\begin{tabular}{|c|c|c|c|c|}
\hline & Modelo 1 & Modelo 2 & Modelo 3 & Modelo 4 \\
\hline Constante & $0,384 * * *$ & $-2,595 * * *$ & $-3,147 * * *$ & $-3,132 * * *$ \\
\hline \multicolumn{5}{|l|}{$\begin{array}{l}\text { Tipo de Delitos del que ha sido Víctima el } \\
\text { Entrevistado/a (Ref.: Sólo Robo con Violencia o } \\
\text { Intimidación) }\end{array}$} \\
\hline Sólo Robo por Sorpresa & $0,658 * * *$ & $0,940 * * *$ & $0,924 * * *$ & $0,918 * * *$ \\
\hline Sólo Hurto & $0,900 * * *$ & $1,211 * * *$ & $1,197 * * *$ & $1,197 * * *$ \\
\hline Robo por Sorpresa y Robo con Violencia o Intimidación & $-0,137 * * *$ & $0,135 * * *$ & $0,128 * * *$ & $0,275 * * *$ \\
\hline Hurto y Robo con Violencia o Intimidación & $1,744 * * *$ & $2,021 * * *$ & $2,035 * * *$ & $2,161 * * *$ \\
\hline Hurto y Robo por Sorpresa & $1,550 * * *$ & $2,117 * * *$ & $2,107 * * *$ & $2,086 * * *$ \\
\hline \multicolumn{5}{|l|}{$\begin{array}{l}\text { Cantidad de veces que ha sido Víctima de Delitos en } \\
\text { el Espacio Público contra las Personas (Ref.: } 1 \text { vez) }\end{array}$} \\
\hline 2 veces & $-0,344 * * *$ & $-0,362 * * *$ & $-0,364 * * *$ & $-0,355 * * *$ \\
\hline 3 o más veces & $-0,033 * *$ & 0,000 & $-0,003$ & $0,060 * * *$ \\
\hline \multicolumn{5}{|l|}{ Edad (Ref.: 60 o más años) } \\
\hline 15 a 29 años & & $0,938 * * *$ & $0,950 * * *$ & $1,133 * * *$ \\
\hline 30 a 44 años & & $0,406 * * *$ & $0,411 * * *$ & $0,507 * * *$ \\
\hline 45 a 59 años & & 0,016 & $0,033 * * *$ & $0,079 * * *$ \\
\hline \multicolumn{5}{|l|}{ Sexo (Ref.: Mujer) } \\
\hline Hombre & & $0,278 * * *$ & $0,278 * * *$ & $0,275 * * *$ \\
\hline \multicolumn{5}{|l|}{ Clasificación Socioeconómica (Ref.: ABC1) } \\
\hline $\mathrm{C} 2$ & & $1,810 * * *$ & $1,816 * * *$ & $1,762 * * *$ \\
\hline $\mathrm{C} 3$ & & $2,002 * * *$ & $2,008 * * *$ & $2,015 * * *$ \\
\hline $\mathrm{D}$ & & $2,136 * * *$ & $2,137 * * *$ & $2,123 * * *$ \\
\hline $\mathrm{E}$ & & $2,074 * * *$ & $2,078 * * *$ & $1,922 * * *$ \\
\hline \multicolumn{5}{|l|}{ Nivel Educacional (Ref.: Post Universitaria) } \\
\hline Básica o Inferior & & $0,067 * *$ & $0,057 * *$ & $0,070 * *$ \\
\hline Media o Equivalente & & $0,123 * * *$ & $0,122 * * *$ & $0,232 * * *$ \\
\hline Superior & & $-0,380 * * *$ & $-0,383 * * *$ & $-0,356 * * *$ \\
\hline \multicolumn{5}{|l|}{ Estado Conyugal (Ref.: Separado/Divorciado) } \\
\hline Casado/a o Conviviente & & $0,160 * * *$ & $0,169 * * *$ & $0,197 * * *$ \\
\hline Soltero/a & & $0,173 * * *$ & $0,176 * * *$ & $0,154 * * *$ \\
\hline Viudo/a & & $1,317 * * *$ & $1,318 * * *$ & $1,362 * * *$ \\
\hline \multicolumn{5}{|l|}{ Aporta al Ingreso del Hogar (Ref.: No) } \\
\hline Sí aporta & & $-0,066 * * *$ & $-0,071 * * *$ & $-0,056 * * *$ \\
\hline $\begin{array}{l}\text { Percepción sobre la delincuencia en el país (Ref.: } \\
\text { Disminuyó) }\end{array}$ & & & & \\
\hline
\end{tabular}


QUINTEROS, Daniel "Delitos del espacio público y el problema de la "cifra negra": una aproximación a la no-denuncia en Chile".

\begin{tabular}{lll}
\hline Se mantuvo & $0,559^{* * *}$ & $0,689 * * *$ \\
Aumentó & $0,600^{* * *}$ & $0,768 * * *$ \\
\hline
\end{tabular}

Tabla 1.1 Resumen de los coeficientes logísticos para modelos sobre la No-Denuncia de Delitos en el Espacio Público Contra las Personas (continuación)

\section{Modelo 1 Modelo 2 Modelo $3 \quad$ Model}

o 4

Cuánto le afecta la Delincuencia en su Calidad de

Vida, de acuerdo a su experiencia personal con el

Delito (Ref.: Mucho)

Nada

$-0,073 * * * \quad-$

$0,150 *$

Poco

$0,081^{* * *} \quad 0,067 *$

Bastante

$0,021 * * * \quad 0,009$

Cree que será víctima de un delito en los próximos

12 meses (Ref.: No)

Sí

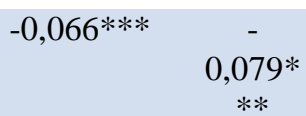

Ha tomado alguna medida para prevenir o

protegerse de la delincuencia durante los últimos 12

meses (Ref.: No)

Sí

Confianza en el Gobierno (Ref.: Mucha)

Ninguna

$0,315 *$

$* *$

Poca

$0,463 *$

**

Confianza en los Tribunales de Justicia (Ref.:

Mucha)

Ninguna

$0,525^{*}$

$* *$

Poca

$0,636^{*}$

Confianza en Carabineros (Ref.: Mucha)

Ninguna

**

Confianza en la Policía de Investigaciones (Ref.:

Mucha)

Ninguna

$0,177 *$

$* *$

Poca 
Polít. crim. Vol. 9, № 18 (Diciembre 2014), Art. 12, pp. 691-712.

[http://www.politicacriminal.cl/Vol_09/n_18/Vol9N18A12.pdf]

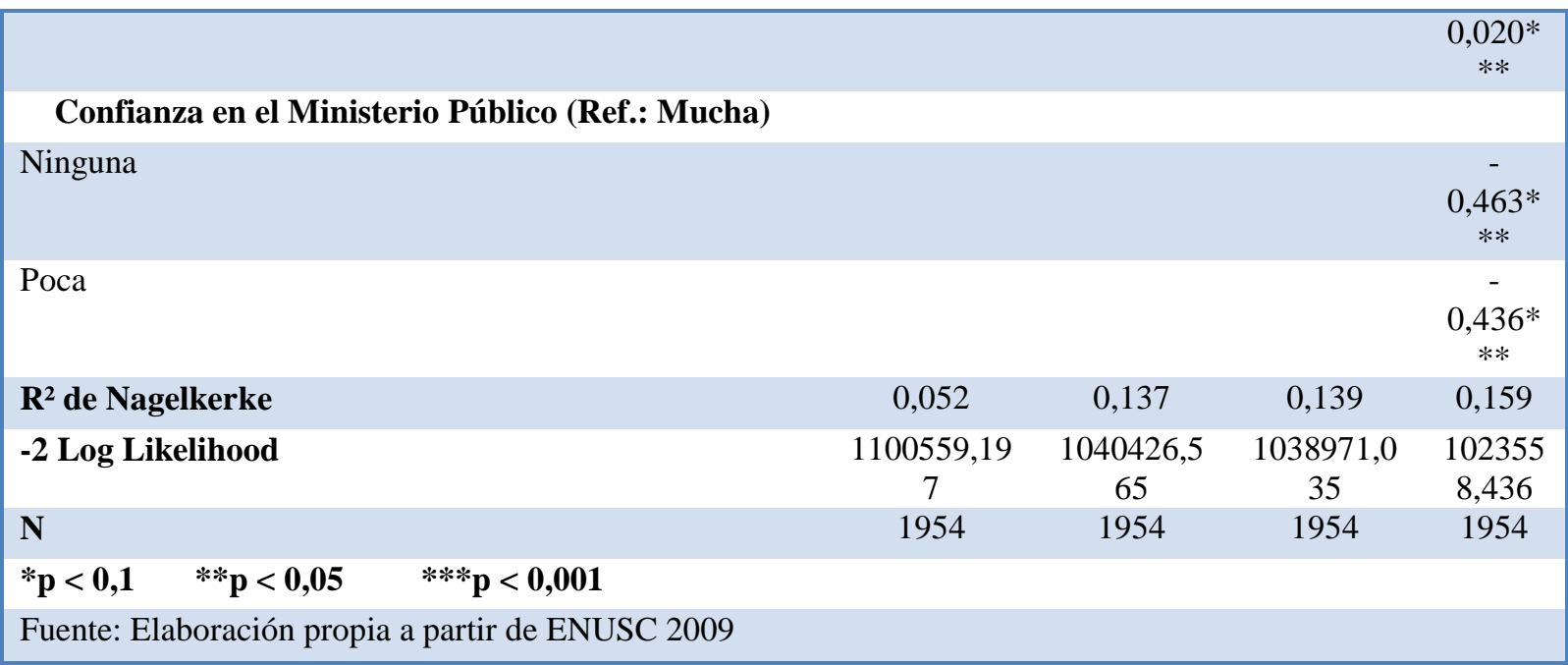

Tabla 1.2 Resumen de los coeficientes de chances para modelos sobre la No-Denuncia de Delitos en el Espacio Público Contra las Personas

\begin{tabular}{|c|c|c|c|c|}
\hline & Modelo 1 & Modelo 2 & Modelo 3 & Modelo 4 \\
\hline Constante & $1,468 * * *$ & $0,075 * * *$ & $0,043 * * *$ & $0,044 * * *$ \\
\hline \multicolumn{5}{|l|}{$\begin{array}{l}\text { Tipo de Delitos del que ha sido Víctima el } \\
\text { Entrevistado/a (Ref.: Sólo Robo con Violencia o } \\
\text { Intimidación) }\end{array}$} \\
\hline Sólo Robo por Sorpresa & $1,931 * * *$ & $2,560 * * *$ & $2,519 * * *$ & $2,505 * * *$ \\
\hline Sólo Hurto & $2,460 * * *$ & $3,357 * * *$ & $3,311 * * *$ & $3,310 * * *$ \\
\hline Robo por Sorpresa y Robo con Violencia o Intimidación & $0,872 * * *$ & $1,144 * * *$ & $1,136 * * *$ & $1,317 * * *$ \\
\hline Hurto y Robo con Violencia o Intimidación & $5,717 * * *$ & $7,547 * * *$ & $7,650 * * *$ & $8,684 * * *$ \\
\hline Hurto y Robo por Sorpresa & $4,714 * * *$ & $8,304 * * *$ & $8,224 * * *$ & $8,053 * * *$ \\
\hline \multicolumn{5}{|l|}{$\begin{array}{l}\text { Cantidad de veces que ha sido Víctima de Delitos en } \\
\text { el Espacio Público contra las Personas (Ref.: } 1 \text { vez) }\end{array}$} \\
\hline 2 veces & $0,709 * * *$ & $0,696 * * *$ & $0,695 * * *$ & $0,701 * * *$ \\
\hline 3 o más veces & $0,967 * *$ & 1,000 & 0,997 & $1,061 * * *$ \\
\hline \multicolumn{5}{|l|}{ Edad (Ref.: 60 o más años) } \\
\hline 15 a 29 años & & $2,555 * * *$ & $2,587 * * *$ & $3,105 * * *$ \\
\hline 30 a 44 años & & $1,501 * * *$ & $1,508 * * *$ & $1,661 * * *$ \\
\hline 45 a 59 años & & 1,016 & $1,034 * * *$ & $1,082 * * *$ \\
\hline \multicolumn{5}{|l|}{ Sexo (Ref.: Mujer) } \\
\hline Hombre & & $1,320 * * *$ & $1,320 * * *$ & $1,317 * * *$ \\
\hline \multicolumn{5}{|l|}{ Clasificación Socioeconómica (Ref.: ABC1) } \\
\hline $\mathrm{C} 2$ & & $6,110 * * *$ & $6,149 * * *$ & $5,826 * * *$ \\
\hline $\mathrm{C} 3$ & & $7,404 * * *$ & $7,449 * * *$ & $7,502 * * *$ \\
\hline $\mathrm{D}$ & & $8,470 * * *$ & $8,475 * * *$ & $8,355 * * *$ \\
\hline $\mathrm{E}$ & & $7,956 * * *$ & $7,988 * * *$ & $6,835 * * *$ \\
\hline
\end{tabular}


QUINTEROS, Daniel "Delitos del espacio público y el problema de la "cifra negra": una aproximación a la no-denuncia en Chile".

\begin{tabular}{|c|c|c|c|}
\hline \multicolumn{4}{|c|}{ Nivel Educacional (Ref.: Post Universitaria) } \\
\hline Básica o Inferior & $1,070^{* *}$ & $1,059^{* *}$ & $1,072 * *$ \\
\hline Media o Equivalente & $1,130 * * *$ & $1,130 * * *$ & $1,261 * * *$ \\
\hline Superior & $0,684 * * *$ & $0,682 * * *$ & $0,700 * * *$ \\
\hline \multicolumn{4}{|c|}{ Estado Conyugal (Ref.: Separado/Divorciado) } \\
\hline Casado/a o Conviviente & $1,173 * * *$ & $1,184 * * *$ & $1,218 * * *$ \\
\hline Soltero/a & $1,189 * * *$ & $1,193 * * *$ & $1,166^{* * *}$ \\
\hline Viudo/a & $3,731 * * *$ & $3,735 * * *$ & $3,903 * * *$ \\
\hline \multicolumn{4}{|c|}{ Aporta al Ingreso del Hogar (Ref.: No) } \\
\hline Sí aporta & $0,936 * * *$ & $0,931 * * *$ & $0,946 * * *$ \\
\hline \multicolumn{4}{|c|}{$\begin{array}{l}\text { Percepción sobre la delincuencia en el país (Ref.: } \\
\text { Disminuyó) }\end{array}$} \\
\hline Se mantuvo & & $1,748 * * *$ & $1,991 * * *$ \\
\hline Aumentó & & $1,823 * * *$ & $2,155 * * *$ \\
\hline
\end{tabular}

Tabla 1.2 Resumen de los coeficientes de chances para modelos sobre la No-Denuncia de Delitos en el Espacio Público Contra las Personas (continuación)

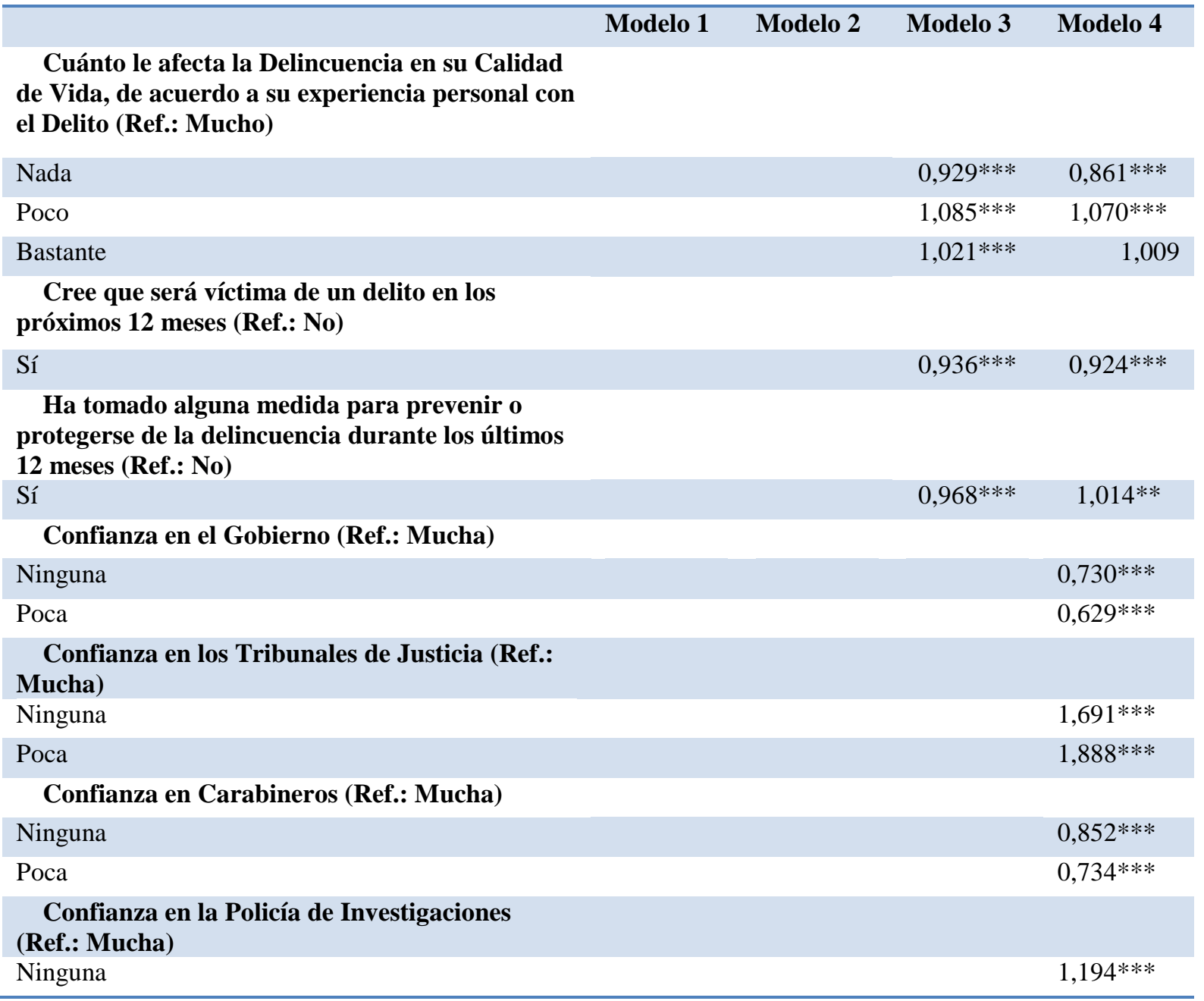


Polít. crim. Vol. 9, № 18 (Diciembre 2014), Art. 12, pp. 691-712.

[http://www.politicacriminal.cl/Vol_09/n_18/Vol9N18A12.pdf]

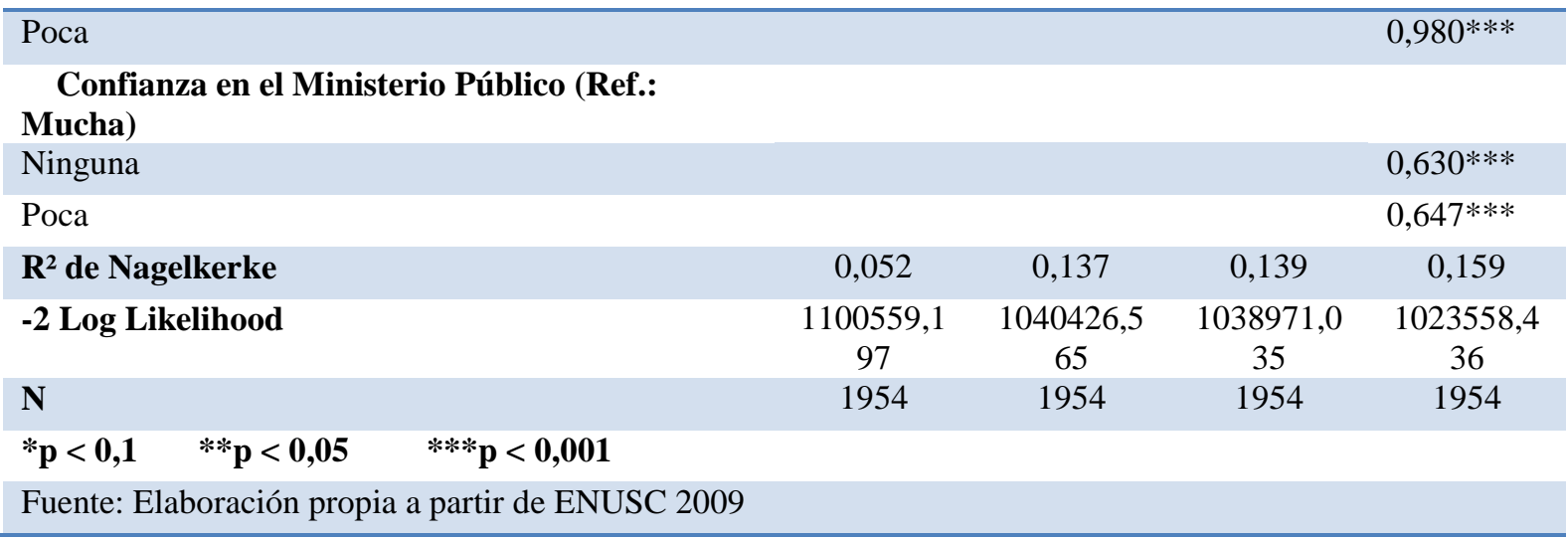

\section{Esquema General del Modelo}

\begin{tabular}{|c|c|c|c|}
\hline Tipo de Variable & $\begin{array}{l}\text { Nombre de } \\
\text { Variable }\end{array}$ & Hipótesis & $\begin{array}{l}\text { Modelo en que } \\
\text { Interviene }\end{array}$ \\
\hline Dependiente & No-Denuncia & \multicolumn{2}{|c|}{$\begin{array}{l}\text { Valor } 0=\text { Denuncia } 1=\text { No Denuncia, puesto que } \\
\text { lo que se intenta explicar es la justamente la no } \\
\text { denuncia. }\end{array}$} \\
\hline \multirow[b]{2}{*}{ Victimización } & Tipo de Delito & \multirow{2}{*}{$\begin{array}{l}\text { El tipo de delito del cual } \\
\text { se haya sido víctima y la } \\
\text { cantidad, puede } \\
\text { condicionar la no- } \\
\text { denuncia. }\end{array}$} & \multirow[b]{2}{*}{$1,2,3$ y 4} \\
\hline & $\begin{array}{l}\text { Cantidad de } \\
\text { Delitos }\end{array}$ & & \\
\hline \multirow{6}{*}{ Sociodemográficas } & Edad & \multirow{6}{*}{$\begin{array}{l}\text { La no-denuncia se } \\
\text { distribuye desigualmente } \\
\text { según distintos grupos } \\
\text { socioeconómicos y } \\
\text { etáreos, con diferencias } \\
\text { según nivel educacional, } \\
\text { estado conyugal y si } \\
\text { aporta ingresos al hogar o } \\
\text { no. }\end{array}$} & \multirow{6}{*}{2,3 y 4} \\
\hline & Sexo & & \\
\hline & $\begin{array}{l}\text { Grupo } \\
\text { Socioeconómico }\end{array}$ & & \\
\hline & Nivel Educacional & & \\
\hline & Estado Conyugal & & \\
\hline & $\begin{array}{l}\text { Aporta Ingresos al } \\
\text { Hogar }\end{array}$ & & \\
\hline \multirow{4}{*}{$\begin{array}{l}\text { Inseguridad y } \\
\text { Reacción frente al } \\
\text { Delito }\end{array}$} & $\begin{array}{l}\text { Percepción sobre } \\
\text { Delincuencia en el } \\
\text { País }\end{array}$ & \multirow{4}{*}{$\begin{array}{l}\text { Quien siente más temor o } \\
\text { cree con mayor fuerza } \\
\text { que será víctima de un } \\
\text { delito, está más } \\
\text { preocupado de la } \\
\text { delincuencia y por tanto, } \\
\text { estará más dispuesto a } \\
\text { denunciar. A la inversa, } \\
\text { para quienes la } \\
\text { delincuencia no les afecta } \\
\text { con mucha fuerza, tienen } \\
\text { mayores probabilidades } \\
\text { de no denunciar los } \\
\text { delitos. }\end{array}$} & \multirow{4}{*}{3 y 4} \\
\hline & $\begin{array}{l}\text { Cuánto le afecta la } \\
\text { Delincuencia su } \\
\text { Calidad de Vida } \\
\end{array}$ & & \\
\hline & $\begin{array}{l}\text { Percepción sobre } \\
\text { posibilidad de ser } \\
\text { Víctima en los } \\
\text { próximos } 12 \text { meses }\end{array}$ & & \\
\hline & $\begin{array}{l}\text { Ha tomado } \\
\text { Medidas para } \\
\text { Prevenir o } \\
\text { Protegerse de la } \\
\text { Delincuencia en }\end{array}$ & & \\
\hline
\end{tabular}


QUINTEROS, Daniel "Delitos del espacio público y el problema de la "cifra negra": una aproximación a la no-denuncia en Chile".

\begin{tabular}{|c|c|c|c|}
\hline & $\begin{array}{l}\text { los últimos } 12 \\
\text { meses }\end{array}$ & & \\
\hline \multirow{5}{*}{$\begin{array}{l}\text { Confianza en } \\
\text { Instituciones }\end{array}$} & Gobierno & \multirow{5}{*}{$\begin{array}{l}\text { Quienes tengan mayor } \\
\text { confianza en las } \\
\text { instituciones encargadas } \\
\text { de la seguridad } \\
\text { ciudadana, tendrán } \\
\text { mayores probabilidades } \\
\text { de denunciar. A la } \\
\text { inversa, no confiar en las } \\
\text { instituciones, lleva a no } \\
\text { denunciar los delitos. }\end{array}$} & \multirow{5}{*}{ Sólo 4} \\
\hline & $\begin{array}{l}\text { Tribunales de } \\
\text { Justicia }\end{array}$ & & \\
\hline & $\begin{array}{l}\text { Carabineros de } \\
\text { Chile }\end{array}$ & & \\
\hline & $\begin{array}{l}\text { Policía de } \\
\text { Investigaciones }\end{array}$ & & \\
\hline & Ministerio Público & & \\
\hline
\end{tabular}

